\title{
Semantic Features of Students' Attitude to Interaction in the Digital Educational Environment
}

\author{
Tatyana Shcherbakova ${ }^{1, *}$, Dynamutdin Misirov $^{2}$, Irina Loseva ${ }^{2}$, and Inna Zhitnaya ${ }^{2}$ \\ ${ }^{1}$ Don state technical University, Gagarina Sq., 1, 344003 Rostov-on-don, Russia \\ ${ }^{2}$ Southern Federal University, Bolshaya Sadovaya str., 105/42, 344006 Rostov-on-don, Russia
}

\begin{abstract}
The characteristics of the main content of the resources and risks of the digital educational environment are considered. The features of understanding the nature and determinants of the success of the interaction of future specialists in the digital educational environment are shown. The article deals with the use of information resources and interaction in the network as a factor of professional and personal growth of students. An idea is given about the features of the semanticization of relations in the digital educational environment. The role of an adequate understanding of the semantic core of the problem in the productivity of students ' project activities is shown. The conditions and ways of achieving success in interaction in the information space within the framework of educational and professional activities are described. The relationship of success with information competence and semantic features of the attitude to interaction in the information space, the motivation of achievement and the expression of the desire for self-development is shown. The results of an empirical study of the peculiarities of students ' attitudes to interaction in the digital environment are described, and their ideas about the limitations and risks of this format of activity are shown. The article presents the material describing the main content of students ' ideas about the characteristics of a successful teacher and a successful student as subjects of interaction in the digital educational environment.
\end{abstract}

\section{Introduction}

The modern realities of the transitive information society encourage the developing subject to look for new opportunities to confirm the demand for their own individuality, to find social confirmation of self-efficacy. In this context, the resources of network interaction become a significant factor in expanding the boundaries of self-presentation, achieving personal, social and professional recognition at various stages of becoming a competitive specialist of the future [1-2]. Modern psychological studies show that in the current conditions of life, the success of the subject is connected, in many respects, with the optimization of interaction strategies in the information space, the understanding of objective and subjective

\footnotetext{
*Corresponding author: tatiananik@list.ru
} 
resources and risks of navigation in the virtual environment, the level of awareness and sematization of the types of relationships with agents of the digital environment $[3,4]$.

The digital environment of the university today is, in a certain sense, a resource platform for students and teachers not only for information and cognitive enrichment, but also for meeting sociogenic needs for self-actualization, personalization and self-realization by significantly expanding the boundaries of personal representation $[5,6]$. The content, psychological determinants, conditions and ways of achieving success here depend not only on the information competence of the student, but also on his attitude to the digital environment, the adequacy of reading its content and purpose in educational and professional activities and personal development. The analysis of research in this direction shows that it is possible to identify the main positions in the content of students ' attitude to the digital environment and the semantics of its capabilities: a source of comprehensive information, the discovery of new forms of activity, the filling of communication deficits, the possibility of testing new roles and image, acquaintance with representatives of their professional community, participation in virtual projects and competitions, a variety of learning forms, a playground. The success of a student as a subject of activity in the digital environment is associated with the ability to position their personality, cognitive, informational, social and communicative competence, motivational and subjective readiness to master innovations [7-9].

Transformations of the modern transitive information society require students to have creativity, mobility and flexibility, critical thinking and the desire for progressive transformation of the individual and optimization of educational and professional activities [10-11]. According to psychologists, the individual basis for determining the student's success in the new contextual field of professional education is the development of adequate semantic schemes, values and meanings, motivation of competence and achievements aimed at mastering productive algorithms of search and cognitive activity, responsibility, personal stability and emotional stability [12-13]. The success of activity in the digital environment is understood as the optimal ratio of the goals and expectations of the subject, the expectations of others and the real results of educational and professional activities and various types of social activities. The productivity of promotion in the digital educational environment of the university in the internal subjective space of the individual correlates with the experience of feelings of pleasure, joy, positive emotions and inspiration, due to the fact that in the semantic field of the individual consciousness of the student, the subjective and objective goals put forward coincided with the results obtained. The work of a future specialist within the framework of new models of professional education implies not only an increased information, but also a semantic load, effective analytical activity, focuses on understanding, and requires certain changes in the attitude to the world. In the modern practice of higher professional education, great importance is attached to the experience of designing future specialists, acquired, including with the involvement of the resources of the digital educational environment of the university, as an individual resource of achievements in the profession in the future. Modern science develops the idea that not only a person's abilities are important, but also the semantic features of his relations to what is happening in real and virtual environments, a positive image of his future, which perform an important function in choosing a development strategy and building a trajectory for the future professional path [14-15]. In modern society, a social order has been clearly formed for the development of multi-level modernization projects in various fields of science and practice, their viability is determined by the competence of future specialists in this field. Of particular importance in this context is the ability of the student to adequately isolate the semantic core of the project, to determine the range of priority issues, based on preliminary monitoring, to systematize the necessary information in a virtual search engine. The project activity of students in the modern system of professional training using distance learning technologies involves the development of their skills to clearly formulate an information request, identify a transaction and determine 
the optimal navigation in the information space. This is determined by the focus on the development of mobility, productivity, flexibility of the cognitive style of future specialists, their ability to create a real innovative product, to contribute to the development of the practice of the professional community. Semantic features of personal relationships set the content, direction and course of human activity, creates the basis for building a system of promising relationships of personal, social and professional level.

The problem-solving algorithms presented in the digital environment are able to awaken the innovative activity of the subject and encourage him to transform himself and change his views on the surrounding reality, which, by and large, is associated with the expansion of consciousness.

In connection with the unlimited factual and analytical information presented in the digital environment, the possibility of going beyond the previously formed image of the subject, including as a future professional, and forming an information basis for self-development increases.

In the present conditions, there is a social order for creative, competent, competitive professionals in their field, aimed at continuous personal and professional self - development in the context of the increased dynamism and entropy of the modern professional space. The high degree of motivation for professional development, as demonstrated by the research results, is directly related to the presence of a future specialist's value attitude to success and preadaptation in the present and future living space. The productive professional development of students at the present time, in the context of global information, is due to their level of meaningfulness and the nature of the value attitude to interaction in the space of the digital educational environment of the university.

It is these characteristics that have a direct impact on the intensity and nature of the activity of future specialists aimed at positioning themselves as a productive person. Today, the trend of professional training of specialists is the development of a student who is able to solve innovative problems, design and implement an individual trajectory of educational and professional development. Since, in the system of higher professional education, program modules are implemented in an interactive space, with the involvement of remote work formats, it is important to take into account the peculiarities of students ' perception by the teacher, others, as well as the assessment of the information competence of the teacher [16].

The quality of interaction in the digital educational environment is determined, to a large extent, by the social-perceptual effects that arise during training, the experience of previously formed relationships.

Semantic features of relations in the educational and professional interaction in the information educational space today play an initiating and structure-forming role, facilitate the development and growth of competence, or create psychological and semantic barriers.

Professional self-awareness is an integral system of new education that arises in the process of professional development of modern students, one of its significant components today is the attitude to oneself and self-esteem as a subject of activity in the digital environment. Here, the personal meaning, the content of subjective attitudes and semantic features of the relationship are important, which together have a stylistic influence on the process of the student's educational and professional activity in the digital educational space. In the modern transitive society, the professional, social and personal success of a student as a subject of information activity is a condition for the formation of a competitive, promising personality, a projection of its resourcefulness. In the new social situation of the student's personality development, the determinants of his success as a subject of educational and professional activity in the new educational environment are transformed, as are the requirements for the degree of cognitive development of the individual and the ability to quickly learn new things. 
In a modern university, professional educational programs acquire a special status, the development of modules of which makes it possible to work out promising algorithms for implementing activity in the digital educational environment of the university.

In a modern university, the achievement of success, the successful development of the student, his positive assessment in the rating system of different levels are directly related to the effectiveness of working with the information constructs of the educational environment.

The undertaken analysis allows us to conclude that the issues of psychological support for the success of the interaction "student-digital environment" and the technology of its achievement are not sufficiently studied. These issues are particularly relevant at the following stages.

\section{Materials and methods}

The study used the questionnaire "I and the digital environment" and the method of content analysis of the essay "Digital educational environment: resources and risks". The study involved students of the Faculty of "Psychology, Pedagogy and Defectology" of DSTU, and students of the Academy of Psychology and Pedagogy of SFU in the number of 146 people.

\section{Discussion}

The analysis of the obtained data shows that students reflect quite well on the cluster of personal characteristics that ensure the successful functioning and promotion of the subject in the digital environment (Fig. 1). Priority is given to information competence and communication skills and mobility, these characteristics, from the point of view of students, form a subjective basis for the development of new formats of interaction in the context of educational and professional activities. Next in importance are such qualities as: willingness and desire to learn new things and the ability of the individual to manage information flows and private data. Students also focus on the importance of forming critical thinking, which allows selecting information, identifying its semantic core, structuring information puzzles, and evaluating its quality. Respondents also note the importance of the individual's ability to adapt quickly, to a new context and work algorithms. 


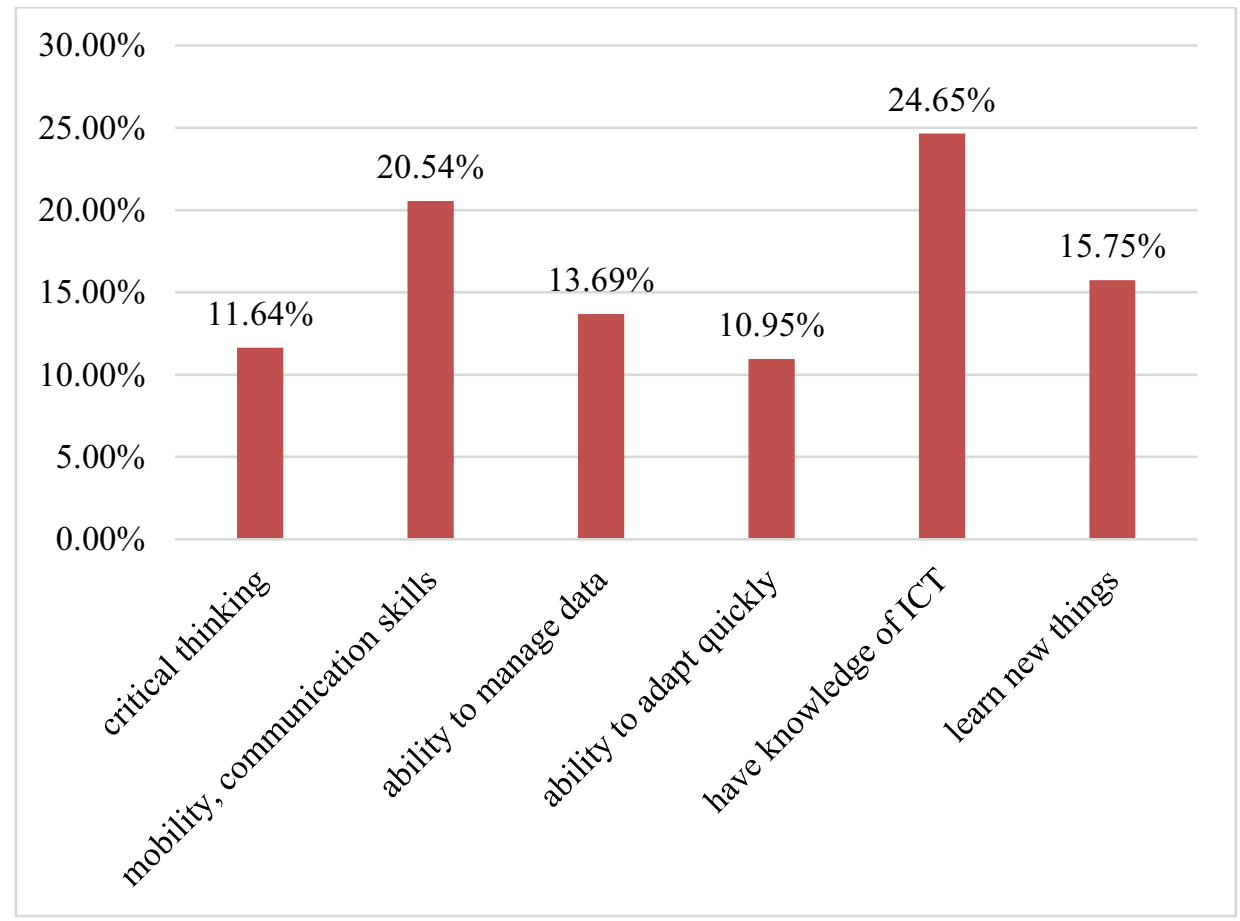

Fig. 1. Personal characteristics for successful functioning in a digital environment

At the same time, as the results show, students believe that the personal and cognitive components of psychological readiness for interaction in the digital environment are more significant than adaptive capabilities.

Analyzing the risks and resources of interaction in the digital environment, students also assessed the difficulties they face in remote learning (Fig. 2).

First of all, the respondents noted somatic risks associated with visual stress and activity restriction. Almost half of the participants talk about increasing the volume of homework and expanding the module of independent work. More than a third of respondents emphasize the risks of communication, in particular, a decrease in the level of communication, which leads to difficulties in the perception of educational material. A certain number of students note the difficulties of self-motivation and self-organization, difficulties in self-modeling the rules of their educational activities.

According to the results of the survey, interesting data were obtained regarding the students ' reflection on the advantages of having a digital educational environment at the university. Students note, first of all, such positions as: the ability to study remotely during various risks that arise in the environment; the presence of visible economic benefits; time savings; the possibility of implementing a more flexible individual educational trajectory; simplification of interaction with teachers; access to the necessary 


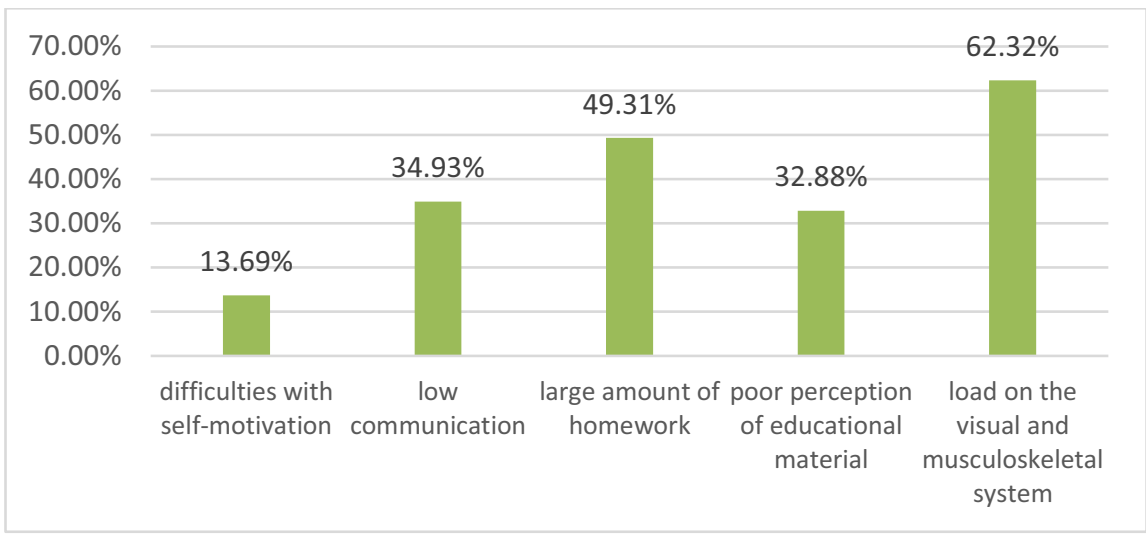

Fig. 2. Assessment of difficulties by students in the remote format

information in electronic libraries. Of the students surveyed, $49 \%$ believe that learning in a relaxed environment increases the level of information acquisition. $36 \%$ of respondents consider interaction in the digital educational environment of the university as a kind of training of readiness for human activity in the modern digital space.

When constructing an associative series to define the digital environment in which we live today, students named the following associations: "sea of communication", "web", "communication", "convenience", "opportunity to experiment", "innovative technologies".

The majority of students, $53 \%$, emphasize that the creation of a digital environment in society today solves the problems of forming an information culture of the individual and improving various spheres of life in society with the help of digital technologies.

When students comprehend the features of interaction in the digital educational environment, a number of specific characteristics were identified: orientation to self-education; individualization of learning; flexibility of the organizational model and regulations; mobility; more time for reflection; high speed of obtaining information; clarity and brevity of statements, visibility.

Based on the analysis of the students ' survey data, a psychological portrait of a person who is able to function productively in a digital environment was compiled. The content of this psychological portrait included the following characteristics:: high level of knowledge, desire for knowledge, knowledge of information and communication technologies, culture of communication on the Internet, adaptability, competent use of information resources, analytical skills, ability to concentrate in the absence of external control, learning ability, desire to receive new information, ability to quickly switch attention, knowledge of the features of the information environment, ability to work with technology, sociability, mobility, openness, ability to quickly navigate in any conditions, critical thinking, developed logic, perseverance, interest, information literacy.

The study of the semantic features of the students ' attitude to interaction in the information educational environment shows that these issues are the subject of reflection and reflection for modern students. Focusing on the importance of information competence and the presence of a common culture of communication in the network, students note the importance of developing a certain cluster of qualities-internal determinants of success. the role of the individual in the digital space. Much attention is paid to the convenience, cost-effectiveness and effectiveness of the distance learning format. At the same time, the questions of the very nature of relationships, their semantic load, fall out of the students ' field of view. This indicates a lack of understanding of the scale of the transition to a new paradigm of relationships in the digital world and the subjective resources and risks associated with it. The semantic 
features of the students ' attitude to interaction in the digital educational environment are associated with a number of positions:

- awareness of their place in the digital educational space;

- understanding the semantic space of this type of interaction;

- understanding the content of personal readiness for productive and constructive functioning in the digital space.

\section{Conclusion}

Today, the student becomes one of the significant figures of progressive changes in professional and social life, which encourages the development of programs of psychological support for his development as a subject of activity in the digital environment. The content of such programs should be aimed at the formation of not only information competence, but also motivational, cognitive, emotional and personal characteristics. A deep understanding of the specifics of the digital environment as a space of activity in different formats allows us to see the trajectories of constructive self-realization in this context.

\section{Reference}

1. N.V. Biryukova, The possibilities of contextual learning for the formation and development of personal meanings of learning among university students. The world of science, culture, and education, 2(75), 99-101 (2019)

2. N.D. Klikunov, Influence of network technologies on the transformation of higher education in Russia. Higher education in Russia, 3, 78-85 (2017)

3. B.V. Markov, Higher education before the challenges of the network society: philosophical plots. Higher education in Russia, 30(2), 100-111 (2021) DOI: 10.31992 / 0869-3617-2021-30-2-100-111

4. A.V. Noskova, D.V. Goloukhova, A.S. Proskurina, T.H. Nguyen, Digitalization of the Educational Environment: Risk Assessment of Distance Education by Russian and Vietnamese Students. Higher Education in Russia, 30(1), 156-167 (2021) doi: 10.31992/0869-3617-2021-30-1-156-167.

5. I.V. Goncharova, G.B. Pronchev, K.G. Pronchev, E.I. Krichever, Accessibility of distance learning forms for Russians, 7, 168-178 (2019)

6. A.G. Kukushkina, Teacher's personal page in the social network as a tool of pedagogical interaction. Higher education in Russia, 29(12), 156-166 (2020) DOI: https://doi.org/10.31992/0869-3617-2020-29-12-156-166

7. I.A.Z. Aidrus, R.R. Asmyatullin, World experience in the use of distance education technologies. Higher education in Russia, 5, 139-145 (2015)

8. T.G. Vezirov, R.D. Huseynov, I.S. Huseynova, E.A. Pirmagomedova, Information and communication subject environment of the university in the development of cognitive activity of future bachelors of pedagogical education, 11, 305-309 (2018)

9. I. Abakumova, G. Zvezdina, A. Grishina, E. Zvezdina, E. Dyakova, Student Attitudes Towards Online Education during the COVID-19 Viral Outbreak of 2020: Distance Learning in a Time of Social Distance September 2020 International Journal of Technology in Education and Science, 4(4), 256-266 (2020) DOI: 10.46328/ijtes.v4i4.107

10. S.A. Krasko, L.G. Sergeeva, N.N. Mikhailova, Application of distance learning in technical universities. Higher education in Russia, 27(6), 135-139 (2018) 
11. B.Ch. Meskhi, L.E. Pustovaya, E.M. Bayan, A.D. Pustovaya, M.G. Zharkova, Remote technologies for mastering practical skills. Higher Education in Russia, 1, 110-114 (2017)

12. T.N. Scherbakova, D.N. Misirov, M.A. Akopyan, L.A. Ogannisyan, The student as a subject of transformative activity in the period of professional training. In the collection: E3S Web of Conferences. XIII International Scientific and Practical Conference "State and Prospects for the Development of Agribusiness - INTERAGROMASH 2020" (2020) https://doi.org/10.1051/e3sconf/202017515013

13. T. Shcherbakova, D. Misirov, M. Akobyan, I. Zhitnaya. Psychological aspects of security culture development for modern students. In the collection: «Web of Conferences» The conference proceedings APPSCONF-2019. Don State Technical Universyty, 03010 (2019) https://doi.org/10.1051/shsconf/20197203010

14. V.V. Prokhorova, E.M. Kobozeva, O.N. Kolomyts, Innovative methods and forms of education as determining factors for improving the effectiveness of the quality of education, 6, 193-198, (2016)

15. C. Rapanta, L. Botturi, P. Goodyear, et al., Online University Teaching During and After the Covid-19 Crisis: Refocusing Teacher Presence and Learning ActivityPostdigital Science and Education, 2 (2020) DOI: https://doi.org/10.1007/s42438-020-00155-y

16. A. Skulmowski, G.D. Re, COVID-19 as an accelerator for digitalization at a German university: Establishing hybrid campuses in times of crisis, Human Behavior \& Emerging Technologies, 2, 212-216 (2020) DOI: https://doi. org/10.1002/hbe2.201 